\title{
Motrivivancia
}

Revista de Educação Física, Esporte e Lazer

LaboMídia

\section{Sistema de proteção do trabalho e do trabalhador da Educação Física: porque somos contra a regulamentação da profissão}

\section{RESUMO}

O texto problematiza a atuação do Conselho Federal de Educação Física e Conselhos Regionais de Educação Física (CONFEF/CREF). Parte das perguntas: $O$ que é a Ação de Inconstitucionalidade (ADin) $\mathrm{n}^{\mathrm{o}} \quad 3.428 / 2005$, origem, desenvolvimento e estágio atual; o que é o CONFEF/CREF e sua (in)capacidade de proteger os trabalhadores(as)? Objetiva subsidiar as posições do Movimento Nacional Contra a Regulamentação do Profissional de Educação Física fortalecer a luta sindical, contribuir com o Movimento Sindical em Defesa do Sistema de Proteção do Trabalho e dos(as) Trabalhadores(as). Como procedimentos de investigação utiliza-se da análise documental. Demonstra que a ADIn procede, tem respaldo constitucional e que a natureza do Conselho não lhe concede prerrogativas de proteção aos trabalhadores(as). Conclui pela defesa organizada do Sistema de Proteção do Trabalho e do(a) Trabalhador(a) da Educação Física a partir das organizações, considerando que a luta pelos direitos é de interesse público, porque dizem respeito à vida dos(as) trabalhadores(as).

PALAVRAS-CHAVE: CONFEF/CREF; Exercício profissional em educação física; Reformas trabalhista e previdenciária; Contrato carteira verde e amarela
Celi Nelza Zülke Taffarel

Pós-doutora em Educação Física pela Universidade de Oldenburg- Alemanha

Professora Titular na Universidade Federal da Bahia (UFBA), Faculdade de Educação, Departamento de Educação Física, Salvador, Brasil taffarel@ufba.br (D) https://orcid.org/0000-0003-3593-4279

Cássia Hack

Doutora em Educação pela Universidade Federal da Bahia

Professora na Universidade Federal do Amapá (UNIFAP), Departamento de Educação, Curso de Educação Física, Macapá, Brasil cassia.hack@gmail.com (D) https://orcid.org/0000-0001-9238-3819

Márcia Morschbacher

Doutora em Educação pela Universidade Federal da Bahia

Professora Adjunta do Centro de Educação da Universidade Federal de Santa Maria (UFSM), Santa Maria, Brasil mm.edufisica@yahoo.com.br (- https://orcid.org/0000-0003-2193-0998

Sidnéia Flores Luz Doutoranda em Educação na Universidade Federal da Bahia (UFBA), bolsista CAPES sidneiaflores@yahoo.com.br D $\underline{\text { https://orcid.org/0000-0002-5989-3144 }}$ 


\title{
Protection system of work and Physical Education workers: why we are against the regulation of the profession
}

\begin{abstract}
This article discusses the role of the Federal Council of Physical Education and its Regional Councils of Physical Education in the defense of Physical Education workers. Part of the questions: What is the Unconstitutionality Action $\mathrm{n}^{\circ} 3.428 / 2005$, origin, development, and current stage; what is CONFEF/CREF and its (in)ability to protect the workers? It aims to support the stance of the National Movement Against the Regulation of Physical Education Professionals strengthens the labor union struggle, contributing to the Union Movement in Defense of the Labor and Workers Protection System. As our investigation procedure, we used documentary analysis. It demonstrates that this ADIn is valid, has constitutional support, and that the activity of CONFEF/CREF does not grant it prerogatives that allow it to protect the workers. It concludes by the organized defense of the Labor Protection System and the Physical Education Worker based on the associations, considering that the fight for rights is of public interest, because it concerns the life of the workers.
\end{abstract}

KEYWORDS: CONFEF/CREF; Professional practice in physical education; Labor and social security reforms; Green and yellow employment contract

\section{Sistema de protección del trabajo y del trabajador de la Educación Física: porque somos contra la regulación de la profesión}

\section{RESUMEN}

El artículo hace problematización a la actuación del Consejo Federal de Educación Física y sus Consejos Regionales en la defensa de los trabajadores(as) de la Educación Física. Parte de las preguntas: ¿Lo que es la Acción de Inconstitucionalidad no 3.428/2005, origen, desarrollo y etapa actual? ¿Lo que es el CONFEF/CREF y su (in)capacidad de proteger los trabajadores(as)? Se tiene como objetivos dar aportes a las posiciones del Movimiento Nacional Contra la Regulación de la Profesional de Educación Física, fortalecer la lucha sindical, contribuyendo con el Movimiento Sindical en Defensa del Sistema de Protección del Trabajo y de los Trabajadores(as). Como procedimiento de investigación fue utilizada un análisis documental. Demuestra que esta ADIn es legítima, tiene respaldo constitucional y que la actuación del Consejo no concede prerrogativas hacia la protección del trabajador(a). Concluye con la defensa organizada del Sistema de Protección Laboral y del Trabajador de Educación Física con base en las asociaciones, considerando que la lucha por los derechos es de interés público, porque atañe a la vida de los trabajadores(as).

PALABRAS-CLAVE: CONFEF/CREF; Ejercicio profesional de educación física; Reformas laboral y de la seguridad social: Contrato verde amarillo 


\title{
O QUE É A ADIN No 3.428/2015? QUEM É A FAVOR E QUEM É CONTRA?
}

\author{
Resolução \\ Considerando nossa fraqueza os senhores forjaram \\ Suas leis, para nos escravizarem. \\ As leis não mais serão respeitadas \\ Considerando que não queremos mais ser escravos. \\ Considerando que os senhores nos ameaçam \\ Com fuzis e com canhões \\ Nós decidimos: de agora em diante \\ Temeremos mais a miséria do que a morte. \\ Considerando que ficaremos famintos \\ Se suportarmos que continuem nos roubando \\ Queremos deixar bem claro que são apenas vidraças \\ Que nos separam deste bom pão que nos falta. [...]
}

(BRECHT, 1981)

Segundo consta na página do Conselho Federal de Educação Física (CONFEF) ${ }^{1}$, entidade que foi presidida pela mesma pessoa ${ }^{2}$ durante seus primeiros 22 anos de existência, o Supremo Tribunal Federal (STF) iniciou no dia 3 de abril de 2020 o Julgamento da Ação Direta de Inconstitucionalidade $n^{\circ} 3.428 / 2005^{3}$, que questiona os artigos $4^{\circ}$ e $5^{\circ}$ da Lei Federal $n^{\circ} 9.696 / 1998$, que dispõe "sobre a regulamentação da Profissão de Educação Física e cria os respectivos Conselho Federal e Conselhos Regionais de Educação Física"4 . Ação Direta de Inconstitucionalidade (ADIn) ${ }^{5}$ é a ação que tem por finalidade declarar que uma lei ou parte dela é inconstitucional, ou seja, contraria a Constituição Federal $(\mathrm{CF})^{6}$.

De autoria da Procuradoria Geral da República (PGR), a ADIn n ${ }^{\circ} 3.428 / 2005$ questiona a constitucionalidade da Lei $\mathrm{n}^{\mathrm{o}} 9.696 / 1998$, em seus artigos $4^{\mathrm{o}}$ e $5^{\mathrm{o}}$, pelo fato de que esta é de iniciativa parlamentar e não da Presidência da República, como prevê a Constituição ${ }^{8}$; portanto, a

\footnotetext{
${ }^{1}$ Ver em: https://www.confef.org.br/confef/comunicacao/noticias/1483.

${ }^{2}$ Tomaram posse em 28 de dezembro de 2020 outra gestão. Ver em: https://www.confef.org.br/confef/conteudo/19.

${ }^{3}$ Ver em: http://portal.stf.jus.br/processos/detalhe.asp?incidente $=2279182$.

${ }^{4}$ Ver em: http://www.planalto.gov.br/ccivil 03/Leis/L9696.htm.

${ }^{5}$ É da norma da Língua Portuguesa acatar duas formas de abreviatura para "Ação Direta de Inconstitucionalidade" sendo ADI e ADIn. Adotamos, neste texto, o uso da abreviatura ADIn.

${ }^{6}$ Ver em: http://www.normaslegais.com.br/guia/Acao-Direta-de-Inconstitucionalidade-ADI.htm.

${ }^{7}$ Os artigos $4^{\circ}$ e $5^{\circ}$ da Lei $n^{\circ}$ 9.696/1998, em seu texto, estabelecem que: "Art. 4o São criados o Conselho Federal e os Conselhos Regionais de Educação Física. Art. 5o Os primeiros membros efetivos e suplentes do Conselho Federal de Educação Física serão eleitos para um mandato tampão de dois anos, em reunião das associações representativas de Profissionais de Educação Física, criadas nos termos da Constituição Federal, com personalidade jurídica própria, e das instituições superiores de ensino de Educação Física, oficialmente autorizadas ou reconhecidas, que serão convocadas pela Federação Brasileira das Associações dos Profissionais de Educação Física - FBAPEF, no prazo de até noventa dias após a promulgação desta Lei." (BRASIL, 1998).

${ }^{8}$ Conforme Artigo 61, parágrafo $1^{\circ}$, inciso II, alínea "e" e art. 84, inciso III da Constituição Federal.
} 
referida lei apresenta vício de iniciativa9 ${ }^{9}$. Os conselhos de fiscalização profissional, de acordo com o autor $^{10}$ desta ADIn, têm natureza jurídica de autarquia, pois desenvolvem atividade típica de Estado e, portanto, integram a Administração Pública indireta. Assim, submetem-se ao disposto na CF e devem ser criados e disciplinados por lei de iniciativa do Executivo ${ }^{11}$.

Segundo o Movimento Nacional Contra a Regulamentação do Profissional da Educação Física (MNCR), deflagrado em agosto de 1999 e que vem nestes 22 anos lutando pela revogação da Lei $n^{\circ}$ 9.696/1998, a mesma assegura interesses corporativos, divide os profissionais da área, sem fundamentos teóricos e epistemológicos consistentes para tal, além de colocar trabalhadores(as) da Educação Física contra os(as) profissionais de outras áreas, o que aprofunda dramaticamente a fragmentação da Classe Trabalhadora.

O Conselho Federal de Educação Física e seus Conselhos Regionais de Educação Física (CONFEF/CREF) almejam que a ADIn seja julgada improcedente, ou que se adie, ainda mais, a decisão a seu respeito. Os argumentos dos que defendem a improcedência desta ADIn são: (a) ao longo de 15 anos, a ADIn sempre foi retirada de pauta. Em 2020, o Ministro Luiz Fux decidiu pautar esta Ação em sessão virtual; (b) os advogados do CONFEF peticionaram solicitando a retirada da ADIn de pauta e a inclusão em pauta de julgamento presencial, o pedido não foi acatado; (c) houve por parte da Advocacia Geral da União (AGU) e Congresso Nacional a defesa da constitucionalidade dos artigos $4^{\circ}$ e $5^{\circ}$ da Lei Federal no 9.696/1998.

O Ministro Luiz Fux, relator da Ação, proferiu o seguinte voto: “[...] conheço da Ação e julgo procedente o pedido para declarar a inconstitucionalidade dos artigos $4^{\circ}$ e $5^{\circ}$ da Lei Federal 9.696/1998, com eficácia ex nunc a partir de vinte e quatro meses após a data do presente julgamento", conforme consta em comunicação do próprio Conselho ${ }^{12}$. E, na sequência do voto, o Relator indica o prazo de dois anos para que o vício de iniciativa seja sanado.

No dia 14 de abril de 2020, os demais integrantes ${ }^{13}$ do Plenário do STF deveriam proferir seus votos. No entanto, no dia 13 de abril de 2020, o CONFEF reiterou pedido de julgamento em sessão presencial. Também foi protocolizada petição do Conselho Regional de Educação Física 1, que abrange os estados do Rio de Janeiro e Espírito Santo (CREF1/RJ-ES), requerendo ingresso nos autos na qualidade de "amicus curiae". A figura do "amicus curiae", ou amigo da corte, surgiu no

\footnotetext{
${ }^{9}$ A lei $\mathrm{n}^{\mathrm{o}}$ 9.696/1998 tem origem no PL n ${ }^{\mathrm{o}}$ 330/1995, de autoria do deputado federal Eduardo Mascarenhas (PSDB/RJ).

${ }^{10}$ Cláudio Fonteles, PGR.

${ }^{11}$ Ver em: https://www.conjur.com.br/2005-mar-11/pgr_contesta regulamentacao educacao fisica. Acesso em 26 abr. 2020 .

${ }^{12}$ Ver: https://www.confef.org.br/confef/comunicacao/noticias/1483.

${ }^{13}$ Ministros Edson Fachin, Alexandre de Moraes, Ricardo Lewandowski e Gilmar Mendes.
} 
Brasil com a Lei $\mathrm{n}^{\mathrm{o}}$ 9.868/1999, que dispõe sobre a ADIn e a ação declaratória de constitucionalidade. Isto significa, segundo Coutinho Neto e Marinho (2019, s. p.), que:

[...] levando em conta a qualidade da satisfação das partes com a solução dada ao litígio, previu-se a possibilidade da presença do amicus curiae, cuja manifestação, com certeza tem aptidão de proporcionar ao juiz condições de proferir decisão mais próxima às reais necessidades das partes e mais rente à realidade do país. [...] $\mathrm{O}$ relator poderá solicitar informações aos tribunais estaduais ou federais a respeito da controvérsia e autorizar, ante a relevância da matéria, a manifestação escrita de pessoas, órgãos ou entidades com interesse na controvérsia, a serem prestadas no prazo de quinze dias.

No dia 13 de abril de 2020, a Ordem dos Advogados do Brasil (OAB) peticionou os autos da referida ADIn, reforçando a importância do julgamento presencial. Em 14 de abril de 2020, no entanto, o Ministro Gilmar Mendes requereu vista dos autos e, com isso, o julgamento foi suspenso.

A prevalecer o voto do Relator, o Conselho terá dois anos, a partir da publicação da decisão, para sanar o alegado vício de iniciativa. No entanto, esta decisão não atende os pedidos do Ministério Público Federal que requer a dissolução imediata das instâncias profissionais e a devolução das anuidades cobradas até aquele momento.

Resgatando excertos da história de criação do Conselho Federal e os Regionais de Educação Física, apontamos que a primeira tentativa de regulamentação da profissão ocorreu ainda no governo Sarney, tendo este vetado o projeto de lei em 1990. A segunda tentativa aconteceu em meados deste mesmo ano, quando setores conservadores do campo da Educação Física, no Congresso Brasileiro da Federação Brasileira das Associações de Professores de Educação Física, aprovaram o escopo da regulamentação da profissão criando um Movimento pela Regulamentação Já (SILVA et al., 2008).

Silva et al (2008) relata que em 1995 foi apresentado ao Congresso Nacional o Projeto de lei $n^{\circ}$ 330/1995, originado em articulação da Associação de Professores de Educação Física do Rio de Janeiro na pessoa do então presidente Jorge Steinhilber. Os principais argumentos usados para favorecer a regulamentação da profissão eram: (a) expulsar os leigos da área; (b) delimitar o mercado de trabalho que, naquele momento, era considerado "terra de ninguém", portanto, o mercado teria um proprietário; (c) cobrar uma anuidade para que o Conselho exercesse a função de fiscalizador. Este projeto de lei transformou-se na Lei $n^{\circ}$ 9.696/1998, que "causou estranheza, por boa parte de profissionais e pesquisadores(as) da área" (SILVA et al., 2008, p. 5), pois foi um processo antidemocrático, construído em bastidores e gabinetes, muito distante de qualquer processo democrático, participativo dos(as) professores(as) de Educação Física. 
Dias Júnior e Lima (2010) referenciam outro elemento central para compreendermos o processo de criação do CONFEF/CREF: a reforma do Estado, realizada pelo governo de Fernando Henrique Cardoso e sustentada na Lei ${ }^{0}$ 9.649/1998 ${ }^{14}$. O artigo 58 desta lei tem como consequência "a transformação dos Conselhos Profissionais em entidades privadas prestadoras de serviços, com a possibilidade de arbitrar sobre organização e estrutura e funcionamento" (DIAS JÚNIOR; LIMA, 2010, p. 66).

Nesta lei, em específico no artigo $\mathrm{n}^{\mathrm{o}} 58$, temos que: “Os serviços de físcalização de profissões regulamentadas serão exercidos em caráter privado, por delegação do poder público, mediante autorização legislativa" (BRASIL, 1998a). Este artigo é acompanhado de 9 parágrafos, dos quais destacamos o seu conteúdo quanto a: não manutenção de vínculo funcional e hierárquico dos conselhos profissionais com os órgãos da Administração Pública, da cobrança de contribuições financeiras anuais de pessoas físicas e jurídicas, do controle interno das atividades financeiras e administrativas e da imunidade tributária total em relação bens, rendas e serviços dos conselhos profissionais (BRASIL, 1998a).

Em 2002, o STF julgou procedente a ADIn $n^{0}$ 1.717-6/Distrito Federal e declarou inconstitucional o caput do artigo 58 e os parágrafos $1^{\circ}$ a $8^{\circ}$. O STF concluiu que não é possível delegar atividades típicas do Estado, no caso dos Conselhos Profissionais: "que abrange até poder de polícia, de tributar e de punir, no que concerne ao exercício de atividades profissionais regulamentadas" (ADIn $\mathrm{n}^{\mathrm{o}} 1.717-6 / \mathrm{DF}$ ) a entidades privadas - o que confirma a natureza autárquica dos conselhos e sua caracterização como pessoas jurídicas de direito público submetidas ao ordenamento legal aplicado à Administração Pública ${ }^{15}$. Nesta questão é que a ADIn $n^{0} 3.428 / 2005$ se apoia para questionar os Artigos $4^{\circ}$ e $5^{\circ}$ da Lei $n^{\circ}$ 9.696/1998.

A legislação brasileira ${ }^{16}$, ao tratar dos conselhos profissionais lhes atribui a seguinte função social, segundo Costa e Valente (2008, p. 8, grifo nosso):

Inicialmente, cabe repisar algumas ideias basilares sobre o papel institucional dos conselhos de fiscalização de profissões liberais. Como já dito, essas entidades

\footnotetext{
${ }^{14}$ Lei n ${ }^{\circ}$ 9.649, de 27 de maio de 1998, que dispõe sobre a organização da Presidência da República e dos Ministérios, e dá outras providências.

15 Apontamos no Estatuto do CONFEF a contradição entre o Artigo $1^{\text {o }}$, que caracteriza o Conselho como "pessoa jurídica de direito público interno sem fins lucrativos" e "autarquias especiais, criados pela Lei Federal n 9.696 , de $1^{\circ}$ de setembro de 1998", que tem "poder delegado pela União para normatizar, orientar, disciplinar e fiscalizar o exercício das atividades próprias dos Profisssionais de Educação Física e das pessoas jurídicas, cuja finalidade básica seja a prestação de serviços nas áreas das atividades físicas, desportivas e similares"; e o Artigo $4^{\circ}$, que delimita que o CONFEF/CREF tem "independência e autonomia, sem qualquer vínculo funcional, técnico, administrativo ou hierárquico com qualquer órgão da Administração Pública” - (CONFEF Res. nº 206, de 07 de novembro de 2010). 
foram criadas como prolongamento do Estado para o atendimento do interesse público, pois o exercício de atividades do Poder Público, decorrentes do poder de polícia, far-se-á sempre em função do interesse da coletividade. Assim, é preciso afastar a compreensão de que os conselhos profissionais existem para defender interesses de seus integrantes, o que não corresponde ao papel institucional que lhes foi atribuido pelo Estado. Os conselhos profissionais não são entidades sindicais ou associativas que representam perante a sociedade os interesses de seus filiados ou associados. O dever legal dos conselhos profissionais é o de zelar pelo interesse público, efetuando, para tanto, nos respectivos campos profissionais, a supervisão qualitativa, técnica e ética do exercício das profissões liberais, na conformidade da lei.

Os Conselhos são um prolongamento do Estado e, com poder de polícia. Nos cabe questionar que Estado é este? Segundo Mascaro (2018, p. 13), se faz necessário superar mistificações teóricas que ainda se limitam apenas a definições jurídicas ou metafísicas sobre o Estado, como por exemplo, “que o Estado é o bem comum e legítimo" (MASCARO, 2018, p. 13). O Estado assume uma forma política, de acordo com a classe dominante, e segundo Valim (2017), vivemos um Estado de Exceção, que é a forma jurídica do Neoliberalismo, em que o econômico prevalece sob a vida dos seres humanos. A Pandemia provocada pelo coronavírus, a COVID-19, demonstrou isto no Brasil, com a política genocida, a necropolítica (MBEMBE, 2018) adotada pelo governo federal.

O que temos na atualidade é o Estado de Exceção - uma sociedade dividida em classes sociais, em que, comprovadamente, prevalecem em termos de Política de Estado e Governo os interesses das classes dominantes. Trataremos de "Reformas", que foram aprovadas tanto no Governo Temer quanto Bolsonaro. Estas "contrarreformas" demonstram como a Classe Trabalhadora tem seus direitos e conquistas históricas solapados.

Analisando a Lei $\mathrm{n}^{\mathrm{0}}$ 9.696/1998 ${ }^{17}$ e a intervenção do CONFEF/CREF, identificamos inconstitucionalidades e arbitrariedades. Uma das principais inconstitucionalidades é que este sistema ataca a autonomia das universidades a quem cabe definir o perfil de atuação dos(as) formados(as) na Universidade, conforme expresso na Constituição Federal - Carta Magna do país -, ou seja, uma lei maior e, que, portanto, não pode ser subsumida por uma lei menor. Apresenta ingerência no campo escolar, cuja regulamentação e acompanhamento das condições de formação para a atuação é responsabilidade do Ministério da Educação (MEC). Além disto, o CONFEF/CREF cobra anuidades ${ }^{18}$, que caracterizam um corporativismo contrário ao que prevê a

\footnotetext{
${ }^{17}$ Dias Júnior e Lima (2011) consideram a Lei $\mathrm{n}^{\circ}$ 9.696/1998 uma lei minimalista, que não define de forma concreta como se organiza e quais são as funções do Conselho.

${ }_{18}$ As anuidades são cobradas de Pessoa Jurídica e de Pessoa Física, neste caso, profissionais com formação em Educação Física nos graus de licenciatura e bacharelado, bem como, aqueles que "até dia 01 de setembro de 1998 ,
} 
legislação sobre Conselhos ${ }^{19}$. Quanto ao inciso III do Art. 2o, os termos estabelecidos em Estatuto do Conselho ${ }^{20}$ declaram a possibilidade de credenciar formados e leigos, neste sentido, contradiz um dos argumentos favoráveis à criação do Conselho. O ponto central questionado é acerca do Sistema de Proteção do Trabalho e do(a) Trabalhador(a), que nada consta na lei que cria o CONFEF/CREF. Não se trata de desviar função do Conselho, mas, sim, de perguntar se proteger os(as) trabalhadores(as) da Educação Física não é de interesse público?

Não se pode duvidar do poder político e jurídico do CONFEF/CREF, visto que, em 22 anos, acumulou uma considerável fortuna com as anuidades de pessoas físicas e jurídicas que lhe permitem atuar fortemente em ações de convencimento político. À guisa de exemplo, no âmbito do estado de São Paulo, o quantitativo inscrito no CREF4/SP soma 164.000 Profissionais de Educação Física (pessoas físicas) mais 13.900 Pessoas Jurídicas empregadoras, perfazendo 177.900 registros $^{21}$. Segundo dados coletados do $\mathrm{CONFEF}^{22}$, são 639.258 registrados como pessoa física e 41.843 como pessoa jurídica, totalizando 681.101 registros. Isto significa que seiscentos e trinta e nove mil e duzentos e cinquenta e oito pessoas físicas - profissionais registrados, e quarenta e um mil e oitocentos e quarenta e três pessoas jurídicas registradas pagam anualmente ${ }^{23}$, o valor de R\$ 385.517.322,06 e R\$ 62.362.807,20 - respectivamente, totalizando R\$ 447.880.129,26 (quatrocentos e quarenta e sete milhões, oitocentos e oitenta mil e cento e vinte e nove reais e vinte e seis centavos) anuais conforme demonstra o Quadro 01 a seguir.

\footnotetext{
tenham comprovadamente exercido atividades próprias dos Profissionais de Educação Física”, aqueles que o Conselho se reserva o direito a credenciar, e, por fim, aqueles por força de lei (cf. Resolução CONFEF no 206/2010).

${ }^{19}$ Esta prerrogativa era garantida pelo parágrafo $4^{\circ}$, do Artigo 58, da Lei no 9.649/1998. Neste parágrafo, estabelecia-se que: "Os conselhos de fiscalização de profissões regulamentadas são autorizados a fixar, cobrar e executar as contribuições anuais devidas por pessoas físicas e jurídicas, bem como preços de serviços e multas, que constituirão receitas próprias, considerando-se título executivo extrajudicial a certidão relativa aos créditos decorrentes." (BRASIL, 1998a). O parágrafo $5^{\circ}$ estabelecia que o controle das atividades financeiras e administrativas dos conselhos de fiscalização de profissões regulamentadas seria realizado pelos seus órgãos internos - sendo que os conselhos regionais deveriam prestar contas anualmente ao seu respectivo conselho nacional e vice-versa.

${ }^{20}$ Resolução CONFEF no 01/99 [Art. 14 inciso III], revogada pela Resolução CONFEF no 032/00 [Art. 17 inciso III], revogada pela Resolução CONFEF n ${ }^{\circ}$ 090/04 [Art. 18 inciso III], revogada pela Resolução CONFEF nº 156/2008 [art. 7 inciso III e IV], revogada pela Resolução CONFEF nº 206/10 [Art. 7 inciso III e IV].

${ }^{21}$ Conforme o Manifesto público do CREF4/SP em relação aos reflexos das medidas de contenção do Covid-19 na área da Educação $\quad$ Física. Disponível em:

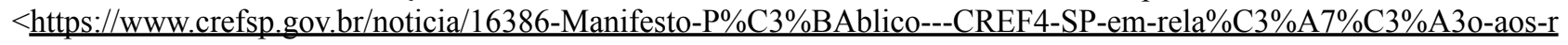
eflexos-das-medidas-de-conten $\% \mathrm{C} 3 \% \mathrm{~A} 7 \% \mathrm{C} 3 \% \mathrm{~A} 3 \mathrm{o}-$ do-COVID-19-na- $\% \mathrm{C} 3 \% \mathrm{~A} 1$ rea-da-Educa $\% \mathrm{C} 3 \% \mathrm{~A} 7 \% \mathrm{C} 3 \% \mathrm{~A} 3 \mathrm{o}-\mathrm{F}$ $\%$ C3\%ADsica $>$. Acesso em: 25 abr.2020.

${ }^{22}$ Disponível em: $<$ https://www.confef.org.br/confef/registrados/>. Acesso em: 24 abr. 2020.

${ }^{23}$ Resolução do CONFEF no 378/2019 “Art. 1 - Fixar o valor das anuidades do exercício de 2020 em: I - Pessoa Física - R\$ 603,07 (seiscentos e três reais e sete centavos); II - Pessoa Jurídica - R\$ 1.490,40 (um mil, quatrocentos e noventa reais e quarenta centavos)".
} 
Quadro 01 - Discriminação do vínculo jurídico, grau de formação de pessoa física, quantitativo de registros de pessoa física por grau de formação e pessoa jurídica, valor das anuidades e total dos

dados

\begin{tabular}{|c|c|c|c|c|}
\hline $\begin{array}{l}\text { Vínculo } \\
\text { jurídico }\end{array}$ & Discriminação & Registros & $\begin{array}{l}\text { Valor R\$ } \\
\text { anuidade }\end{array}$ & R\$/ano \\
\hline \multirow{4}{*}{$\begin{array}{l}\text { Pessoa } \\
\text { Física } \\
\text { (PF) }\end{array}$} & Licenciados(as) & 298.095 & \multirow{3}{*}{603,07} & $179.772 .151,65$ \\
\hline & Bacharéis(las) & 309.635 & & $186.731 .579,45$ \\
\hline & Provisionados(as) & 31.528 & & $19.013 .590,96$ \\
\hline & $\begin{array}{r}\text { Total registro } \\
\text { PF }\end{array}$ & 639.258 & $\begin{array}{r}\text { Total } \\
\text { PF }\end{array}$ & $385.517 .322,06$ \\
\hline \multirow[t]{2}{*}{$\begin{array}{l}\text { Pessoa } \\
\text { Jurídica }\end{array}$} & $\begin{array}{l}\text { Estabelecimentos } \\
\text { prestadores de serviços } \\
\text { em atividade fisica }\end{array}$ & 41.843 & $1.490,40$ & $62.362 .807,20$ \\
\hline & $\begin{array}{r}\text { Total de } \\
\text { registros } \\
\end{array}$ & 681.101 & $\begin{array}{r}\text { Total } \\
\text { RS } \\
\end{array}$ & $447.880 .129,26$ \\
\hline
\end{tabular}

Fonte: Elaboração autoral a partir das informações disponibilizadas na página do CONFEF recolhidas nos dias 24 e 25 de abril/2020.

Portanto, não é possível subestimar a força de uma instituição, na sociedade capitalista, sem considerar quem a financia e quanto arrecada, qual sua função social e como define o que são “interesses públicos". E, com base nestes dados constatamos que quem financia, majoritariamente, o CONFEF/CREF são os(as) Licenciados(as), Bacharéis(las), Provisionados(as) para obter a "proteção" do mercado de trabalho.

\title{
O QUE É O SISTEMA DE PROTEÇÃO DO TRABALHO E DO(A) TRABALHADOR(A)?
}

\author{
[...] Considerando que existem grandes mansões \\ Enquanto os senhores nos deixam sem teto \\ Nós decidimos: agora nelas nos instalaremos \\ Porque em nossos buracos não temos mais condições de ficar. \\ Considerando que os senhores nos ameaçam \\ Com fuzis e canhões \\ Nós decidimos: de agora em diante \\ Temeremos mais a miséria do que a morte.
}

(BRECHT, 1981)

Castioni (2008) demonstra-nos, historicamente, a luta dos(as) trabalhadores(as), suas reivindicações e suas organizações, desde a sua origem para firmar na legislação brasileira um Sistema de Proteção do trabalho e do(a) trabalhador(a), o que nos remete aos séculos XVIII e XIX, na passagem do feudalismo na Europa à chamada Primeira Revolução Industrial. O que queremos destacar é que foram muitos anos de luta para que, na década de 1930 e início dos anos 1940, direitos duramente conquistados como salário-mínimo, férias, seguridade social, assistência, 
previdência, saúde, direito a greve, entre outros, entrassem no marco legal e tivéssemos, por fim, em 1943, o Decreto-Lei n ${ }^{\circ} 5.452$, de $1^{\circ}$ de Maio de 1943, aprovando a Consolidação das Leis do Trabalho (CLT).

A CLT responde também a uma necessidade de organizar o marco legal de proteção dos(as) trabalhadores(as) em torno de suas reivindicações, que eram tratadas nos oito capítulos e 922 artigos a respeito da identificação profissional, duração da jornada de trabalho, salário-mínimo, férias anuais, segurança e medicina do trabalho, proteção do trabalho da mulher, das crianças, da previdência social e regulamentação dos sindicatos da Classe Trabalhadora.

O que constatamos nesta obra de Castioni (2008) é que, apesar de toda a luta da Classe Trabalhadora brasileira e da construção do Sistema de Proteção no Brasil, prevalecia uma tendência de que cada vez menos trabalhadores(as) ingressavam neste sistema em decorrência do mercado informal, do trabalho flexibilizado, precarizado. Segundo Castioni (2008, p. 6): "o tamanho do mercado de trabalho que tem proteção social no país não passava de um terço de sua força de trabalho".

Perguntamo-nos o que aconteceu nos últimos anos com o trabalho humano e com o sistema de proteção do trabalho e do(a) trabalhador(a). Arrizabalo Montoro (2014), demonstra que o capital, para manter taxas de lucro, desvaloriza a força de trabalho, para barateá-las, com a superexploração e perda de direitos - em geral, no campo das relações trabalhistas, mas também de acesso aos serviços públicos e direitos democráticos. O autor explica-nos que o conjunto de regulamentações, que limitam a utilização irrestrita da força de trabalho (o trabalho precarizado, superexplorado), é um obstáculo ao processo de acumulação de capital. Conforme o autor:

Estas regulamentações não são, certamente, concessões das burguesias, senão conquistas arrancadas pelos trabalhadores. Mas no marco do capitalismo há um limite intransponível: o que marca o limiar de uma rentabilidade suficiente. Por isso, nunca se pode falar de consolidação dessas conquistas, já que sempre estarão no alvo da classe capitalista, especialmente à medida que as contradições da acumulação capitalista intensificam-se e, portanto, em sua máxima expressão que são as crises, utilizadas pelo capital para questionar os direitos operários e inclusive democráticos. (ARRIZABALO MONTORO, 2014, p. 404, tradução nossa). ${ }^{24}$

\footnotetext{
24 "Estas reglamentaciones no son, desde luego, concessiones de las burguesías, sino conquistas arrancadas por los trabajadores. Pero em marco del capitalismo hay um límite infranqueable: el que marca el umbral de una rentabilidad suficiente. Por eso, nunca se puede hablar de consolidación de esas conquistas, ya que siempre estarán en el punto de mira de classe capitalista, especialmente a medida que las contradiciones de la acumulación capitalista vayan intensificándose $\mathrm{y}$, por tanto, em su máxima expresión que son las crisis, utilizadas por el capital para cuestionar los derechos obreiros e incluso democráticos" (ARRIZABALO MONTORO, 2014, p. 404).
} 
O que se persegue com a perda ou destruição de direitos e com a desregulamentação do mercado de trabalho? Conforme o autor, busca-se a liberdade de exploração: "[...] se trata de alcançar maior liberdade possível para explorar a força de trabalho, sem restrições" ${ }^{25}$ ou, dito de outro modo, “[...] um elemento de destruição de forças produtivas, ou, se preferir, uma mostra de retrocesso civilizatório"26 (ARRIZABALO MONTORO, 2014, p. 405, tradução nossa).

Este movimento de destruição das conquistas dos(as) trabalhadores(as), ocorre no Brasil, principalmente após o golpe de 2016, que destituiu a presidenta legitimamente eleita ${ }^{27}$, sem que esta tenha cometido crime, conforme exposto no pedido de anulação da decisão condenatória ${ }^{28}$. Aprofundando o golpe de 2016, teremos um aparato legal sendo encaminhado e aprovado no parlamento brasileiro, pelas forças de extrema direita, direita, conservadora, burguesa, da elite escravocrata, latifundiária, fundamentalista, policialesca e judicialesca instalada no parlamento brasileiro. E temos aí aprovadas as medidas da Reforma Trabalhista e Reforma da Previdência e, em compasso de espera, a Carteira Verde e Amarela sob Medida Provisória (MP) nº 905/2019, que caducou no Senado, mas que, provavelmente, voltará a ser encaminhada pelo atual presidente além da PEC no 32/2020 (Reforma Administrativa) e as PECs nos. 186, 187 e $188^{29}$.

\section{VAMOS NOS PERGUNTAR SOBRE O QUE PERDEM OS(AS) TRABALHADORES(AS) COM ESTAS REFORMAS?}

[...] Considerando que está sobrando carvão Enquanto nós gelamos de frio por falta de carvão

Nós decidimos que vamos tomá-lo

Considerando que ele nos aquecerá Considerando que os senhores nos ameaçam Com fuzis e canhões

Nós decidimos: de agora em diante Temeremos mais a miséria do que a morte. [...] (BRECHT, 1981)

Valendo-nos da nota técnica $\mathrm{n}^{\mathrm{o}} 178$ de maio de 2017, do Departamento Intersindical de Estatística e Estudos Socioeconômicos (DIEESE) ${ }^{30}$, que demonstra em 12 pontos, os prejuízos para

\footnotetext{
25 "[...] se trata de lograr la mayor libertad posible para explotar la fuerza de trabajo, sin restriciones" (ARRIZABALO MONTORO, 2014, p. 405).

26 "[...] un elemento de destruicción de fuerzas productivas o, si prefere, una muestra de retroceso civilizatorio" (ARRIZABALO MONTORO, 2014, p. 405).

${ }^{27}$ Resolução do Senado Federal no 35 de 31/08/2016. Ver em: http://legis.senado.leg.br/norma/562339.

${ }^{28}$ Ver em: https://www.jota.info/wp-content/uploads/2016/09/MS-JUSTA-CAUSA 29092016 22h05 final-2.pdf.

${ }^{29}$ Estas PECs compõem o chamado Plano Mais Brasil.

30 A íntegra da nota técnica $\mathrm{n}^{\circ} 178$ de maio de 2017 DIEESE está disponível em: https://www.dieese.org.br/notatecnica/2017/notaTec178reformaTrabalhista.html.
} 
a Classe Trabalhadora com a Reforma Trabalhista ${ }^{31}$, desenvolvemos uma síntese para a compreensão do que está posto:

1) Desonera as empresas e onera os(as) desempregados(as) com o pagamento da contribuição previdenciária para aqueles(as) que acessarem o seguro-desemprego.

2) Ao invés de promover empregos, facilita a demissão de trabalhadores(as) e pode estimular a informalidade (sem carteira de trabalho assinada), a depender da classificação das multas, do enquadramento por porte econômico do infrator e da natureza da infração, que serão definidos posteriormente pelo Executivo Federal. A proposta enfraquece mecanismos de registro, fiscalização, punição e determina a redução de custos com demissão.

3) No setor bancário, aumenta a jornada de trabalho para todos os(as) trabalhadores(as), exceto para a função de caixa; libera a abertura das agências bancárias e o trabalho aos sábados. Este aumento da jornada de trabalho tem potencial de ampliar o desemprego: a cada 2 trabalhadores(as) com jornadas de 44 horas semanais, um poderá ser demitido.

4) Amplia a desregulamentação da jornada de trabalho instituída na reforma trabalhista de 2017 com a liberação do trabalho aos domingos e feriados, sem pagamento em dobro, pago apenas se o(a) trabalhador(a) não folgar ao longo da semana.

5) Promove a negociação individual e a fragmentação das normas por meio de Acordos Coletivos de Trabalho.

6) Retira o sindicato das negociações de Participação nos Lucros e Resultados (PLR) e amplia o número máximo de parcelas, de 2 para 4, ao longo do ano, caminhando para transformar a PLR em parcela variável cada vez maior do salário.

7) Dificulta a fiscalização do trabalho, inclusive em situações de risco iminente. Retira do sindicato a autoridade para também interditar local de trabalho com risco iminente.

8) Institui o Conselho do Programa de Habilitação e Reabilitação Física e Profissional, Prevenção e Redução de Acidentes do Trabalho, sem participação das representações dos trabalhadores(as) e nem mesmo do Ministério da Saúde, no contexto da recente flexibilização das Normas Regulamentadoras da Saúde e Segurança do Trabalho promovida pelo governo. Além disso, esse Conselho entra em conflito com a orientação da Organização Internacional do Trabalho, de criar espaços tripartites para tratar dos temas relativos à saúde do(a) trabalhador(a).

\footnotetext{
${ }^{31}$ A Reforma Trabalhista, de acordo com o DIEESE, começou em 2017 com as leis $\mathrm{n}^{\mathrm{o}} 13.467$ e $\mathrm{n}^{\mathrm{o}} 13.429$ (da terceirização), e prosseguiu com a Medida Provisória da liberdade econômica, convertida na lei no ${ }^{\text {13.8.874/2019. }}$
} 
9) Cria um Fundo que será gerido por esse Conselho. As fontes desse Fundo serão as condenações de ações civis públicas trabalhistas e os valores arrecadados nas condenações por dano moral coletivo constantes nos Termos de Ajuste de Conduta. O Programa de Habilitação e Reabilitação Física e Profissional, Prevenção e Redução de Acidentes do Trabalho se restringe ao ambiente do trabalho, deixando de fora as demais situações como trabalho escravo, trabalho infantil, fraudes nas relações de trabalho, irregularidades trabalhistas na administração pública, liberdade sindical, promoção de igualdade de oportunidades, combate à discriminação no trabalho, entre outras. Apesar do escopo restrito, parte dos recursos que constituem o fundo são de ações oriundas desse escopo mais abrangente, por exemplo, recursos de infrações relacionadas a trabalho infantil, e que, no novo desenho, não serão utilizados em ações de reparação sobre esse tema.

10) Altera a regra para concessão do auxílio-acidente: incluindo no texto um vago "conforme situações discriminadas no regulamento", que será definido por meio de uma lista a ser elaborada pela Secretaria Especial de Previdência e Trabalho do Ministério da Economia. Muda o valor do auxílio-doença de $50 \%$ do salário-benefício (com a reforma, a média de todas as contribuições) para $50 \%$ do benefício de aposentadoria por invalidez.

11) Institui multas que variam de $R \$ 1$ mil a $R \$ 50$ mil por infrações que atinjam os(as) trabalhadores(as) de forma coletiva (o que será modulado pelo porte da empresa) e multas entre R\$ 1 mil a R\$ 10 mil para situações em que o fato gerador da infração esteja relacionado a um trabalhador específico. A gravidade da infração será definida posteriormente, o que pode enfraquecer a capacidade de punição às empresas que cometam infrações trabalhistas.

12) Revoga 86 itens da CLT, entre os quais, direitos e medidas de proteção ao trabalho, como o artigo 160, que estabelece que "Nenhum estabelecimento poderá iniciar suas atividades sem prévia inspeção e aprovação das respectivas instalações pela autoridade regional competente em matéria de segurança e medicina do trabalho".

Quanto à perversa reforma da Previdência, Emenda Constitucional no 103/2019, de 12 de novembro de 2019, que alterou o sistema de previdência social e estabeleceu regras de transição e disposições transitórias, destacamos ${ }^{32}$ que, além de quebrar com o tripé constitucional que articulava a Seguridade Social, constituída pela Assistência, Saúde e Previdência, a Reforma acabou com o direito da aposentadoria por solidariedade de classe para a maioria absoluta dos(as) trabalhadores(as), prejudicou a grande maioria dos(as) trabalhadores(as) brasileiros(as), sobretudo aos mais pobres: criou a idade mínima de 65 anos para homens e 62 para mulheres, aumentou o

\footnotetext{
${ }^{32}$ Ver estudo do DIEESE disponível em: https://www.dieese.org.br/estudotecnico/reformaPrevidencia2019.html. Acesso em: 24 abr. 2020.
} 
tempo mínimo de contribuição (de 15 para 20 anos), reduziu o valor das pensões, desvinculou o piso de benefícios do salário mínimo, exigiu contribuição mínima do(a) agricultor(a) familiar, criou o sistema de capitalização privada, reduziu os benefícios de assistência social, dentre outras medidas.

$\mathrm{Na}$ esteira destes ataques, temos a PEC n ${ }^{\mathrm{o}} 32 / 2020$ e as PECs nos.186, 187 e 188, que visam reformar o Estado, reduzindo os investimentos públicos, retirando os direitos dos/as servidores/as públicos nas três esferas (federal, estadual e municipal) e precarizando os serviços públicos - o que atinge diretamente a população mais pobre, que depende dos serviços públicos.

É explícito que não há absolutamente nada que beneficie o(a) Trabalhador(a) neste conjunto de ataques que destroçam os direitos duramente conquistados durante anos de luta árdua e contínua dos sindicatos, movimentos sociais populares, partidos políticos e setores progressistas da sociedade em geral.

\title{
O QUE FAZER?
}

\author{
[...] Considerando que para os senhores não é possivel \\ Nos pagarem um salário justo \\ Tomaremos nós mesmos as fábricas \\ Considerando que sem os senhores, tudo será melhor para nós. \\ Considerando que os senhores nos ameaçam \\ Com fuzis e canhões \\ Nós decidimos: de agora em diante \\ Temeremos mais a miséria que a morte. [...]
} (BRECHT, 1981)

Ao questionar a capacidade do CONFEF/CREF de proteger os(as) profissionais de Educação Física, e considerarmos isto de interesse público, através da demonstração do que os(as) trabalhadores(as) perderam com as Reformas Trabalhista e da Previdência e, o que ainda perderão com a aprovação do conteúdo destrutivo da MP nº 905/2019 e das PECs nos. 32, 186, 187 e 188, o fazemos para nos perguntar sobre: o que fazer?

A luta dos(as) trabalhadores(as), por melhores condições de vida e de trabalho e por uma sociedade justa tem se tornado cada vez mais árdua à medida que vão sendo aplicados os planos de ajuste estrutural do capital, que visam destruir as forças produtivas, recompor taxas de lucros dos setores rentistas da economia, em detrimento do atendimento das reivindicações da Classe Trabalhadora. 
Com a pandemia ocasionada pelo novo Coronavírus somada à crise econômica, social, política e ambiental, agrava-se a situação dos(as) trabalhadores(as). A Pandemia acelera e deixa à mostra a perversidade do modo de produção capitalista. Aceleram-se os ataques aos serviços públicos, a perda de empregos, as demissões, a informalidade, as reduções de salários e, a retirada de direitos duramente conquistados.

Considerando, portanto, a necessidade de preservar, proteger a Classe Trabalhadora, os(as) trabalhadores(as) profissionais da Educação Física, como um interesse público, devemos seguir atentos na luta, independentemente da aprovação ou não da ADIn n ${ }^{0} 3.428 / 2005$.

Concordamos que a extinção do CONFEF/CREF por mecanismos jurídicos é sem dúvida um avanço. Contudo, é necessário mais, segundo o conteúdo da poética de Brecht. É necessária uma Resolução dos(as) próprios(as) trabalhadores(as), que não seremos mais subsumidos por um sistema cujas referências éticas e morais estão pautadas na lógica corporativa própria do mercado capitalista.

É necessária a luta cotidiana, conforme defende o MNCR em sua página ${ }^{33}$ e em sua prática, não separando as premissas teóricas das pragmáticas, que todos e todas compreendam por que o sistema CREF/CONFEF foi criado e existe. Compreender que o Conselho sustenta a divisão dos(as) trabalhadores(as), extrapola suas instâncias para interferir desde os órgãos de fomento à pesquisa, as instâncias acadêmicas nas universidades e nos projetos pedagógicos das escolas, do sistema de saúde, esportivo e de lazer e; tem interferido na autonomia das universidades no que diz respeito à formação unificada de profissionais de Educação Física e, tensionado para uma divisão que coloca trabalhadores(as) uns contra os outros (CRUZ, 2009; DIAS JUNIOR; LIMA, 2010; DIAS; TEIXEIRA, 2010).

As lições que temos que tirar neste momento de crise civilizatória é que o CONFEF/CREF não tem a capacidade, a finalidade e nem o interesse de proteger os(as) trabalhadores(as) e que, temos que nos auto organizar com base fundada nos princípios da economia socialista.

\section{PARA CONCLUIR}

[...] Considerando que o que o governo nos promete sempre Está muito longe de nos inspirar confiança Nós decidimos tomar o poder Para podermos levar uma vida melhor.

\footnotetext{
${ }^{33}$ Ver em: http://mncref.blogspot.com/e https://www.facebook.com/MNCRef.
} 
Considerando: vocês escutam os canhões Outra linguagem não conseguem compreenderDeveremos então, sim, isso valerá a pena Apontar os canhões contra os senhores!

(BRECHT, 1981)

A análise teórica realizada permite, como conclusão política: (1) reconhecer que a legislação, ao tratar da função social dos Conselhos enquanto prolongamento do Estado, destaca a problemática do interesse público. E, assim, perguntamos: manter direitos de uma categoria não seria de interesse público?; (2) reconhecer que organizações corporativas, baseadas nos princípios da lógica capitalista, defendem exclusivamente reserva de mercado e, para tanto, cobram anuidades de pessoas físicas e jurídicas; (3) faz-se necessária a defesa organizada do Sistema de Proteção do Trabalho e do(a) Trabalhador(a) da Educação Física, com base em premissas de um projeto histórico, cujos princípios são os próprios da economia socialista (MÉSZÀROS, 2002), estes para além da defesa dos campos de trabalho, cindidos pela regulamentação da profissão; (4) a luta histórica pela emancipação da Classe Trabalhadora para superar o modo de produção capitalista possibilitará superar o estágio de constrangimento que vivemos, em que um sistema como o do Conselho Federal e Regionais de Educação Física age no prolongamento do Estado Burguês, com força de polícia; (5) que a luta pelos direitos, conquistas como, trabalho digno, em condições, dignas, com salários dignos, carreira, seguridade social, assistência, previdência, saúde, e direito à organização, são de interesse público porque dizem respeito à vida dos(as) trabalhadores(as) da Educação Física; (6) que cabe fortalecer as organizações que defendem tudo aquilo que garante a vida dos(as) trabalhadores(as) da Educação Física, com destaque os sindicatos.

Destacamos ainda nesta síntese conclusiva os princípios de funcionamento da alternativa socialista, segundo Mészàros (2002, p. 50, grifo do autor):

[...] a regulação, dos produtores associados, do processo de trabalho orientada para a qualidade em lugar da superposição política ou econômica de metas de produção e consumo predeterminadas e mecanicamente quantificadas; a instituição de contabilidade socialista e do legítimo planejamento de baixo para cima, em vez de pseudo planos fictícios impostos à sociedade de cima para baixo, condenados a permanecer irrealizáveis por causa do caráter insuperavelmente conflitante deste tipo de sistema; a mediação dos membros da sociedade por meio de troca planejada de atividades, em vez de direção política arbitríria tanto da força de trabalho como de bens no sistema do capital e pós-capitalista do tipo soviético ou da fetichista troca de mercadoria do capitalismo; a motivação de cada produtor por intermédio de um sistema autodeterminado de incentivos morais e materiais, em vez de sua regulação pela cruel imposição de normas stakhanovistas ou pela tirania do mercado; tornar significativa e realmente possível a responsabilidade voluntária assumida pelos membros da sociedade por meio do exercício de seus poderes de tomada de decisão, em vez da irresponsabilidade institucional que marca e vicia todas as variedades do sistema do capital. 
Ainda segundo Mészàros (2002, p. 50), “a necessidade de sua implementação não resulta de ponderações teóricas abstratas, mas da crise estrutural cada vez mais profunda do sistema do capital global".

Para finalizar, reconhecemos que a luta da Classe Trabalhadora é necessária, é vital, é contínua, é permanente, é internacional e é para vencer.

\section{REFERÊNCIAS}

ARRIZABALO MONTORO, Xabier. Capitalismo y Economía Mundial: bases teóricas y análisis empírico para la comprensión de los problemas económicos del siglo XXI. Madrid: Instituto Marxista de Economía, 2014.

BRASIL. Lei no 9696, de 01 de setembro de 1998. Dispõe sobre a regulamentação da Profissão de Educação Física e cria os respectivos Conselho Federal e Conselhos Regionais de Educação Física. Diário Oficial da União, Brasília, 02 set. 1998. Seção 1, p. 1. Disponível em http://www.planalto.gov.br/ccivil 03/Leis/L9696.htm. Acesso em: 24 abr. 2020.

BRASIL. Lei no 9.649, de 27 de maio de 1998. Dispõe sobre a organização da Presidência da República e dos Ministérios, e dá outras providências. Diário Oficial da União, Brasília, 28 mai.1998 e retificado em 5 jun. 1998. (1998a) Disponível em: http://www.planalto.gov.br/ccivil 03/LEIS/L9649cons.htm. Acesso em: 27 abr. 2020.

BRASIL. ADIn no 3428/DF- Distrito Federal. Ação Direta de Inconstitucionalidade. Supremo Tribunal Federal. Tribunal Pleno. Julga a inconstitucionalidade do sistema CONFEF/CREF sob os artigos $4^{\circ}$ e $5^{\circ}$ da Lei Federal n. 9.696/1998 que regulamentou a profissão de Educação Física. Disponível em: http://portal.stf.jus.br/processos/detalhe.asp?incidente=2279182. Acesso em: 24 abr. 2020.

BRASIL. Emenda Constitucional $\mathbf{n}^{\mathbf{0}} \mathbf{1 0 3 / 2 0 1 9}$. Altera o sistema de previdência social e estabelece regras de transição e disposições transitórias. Disponível em:

http://www.planalto.gov.br/ccivil 03/constituicao/emendas/emc/emc103.htm. Acesso em: 24 abr. 2020.

BRECHT, Bertold. A Resolução. In: Os dias da Comuna. São Paulo: Editora Caminho, 1981. Seção 3 da peça que Brecht escreveu em 1948-1949, traduzida para o português por Fernando Peixoto.

CASTIONI, Remi. O sistema de proteção ao trabalho no Brasil. Campinas: Autores Associados, 2008.

COSTA, Beatriz Rezende Marques; VALENTE, Manoel Adam Lacayo. Responsabilidade Social dos

Conselhos Profissionais. Brasília: Biblioteca Digital da Câmara dos Deputados/Centro de Documentação e Informação. Consultoria Legislativa: ESTUDO. Novembro, 2008. Disponível em:

http://bd.camara.gov.br/bd/handle/bdcamara/1714. Acesso em: 27 abr. 2020.

COUTINHO NETO, Francisco Leocádio Ribeiro; MARINHO, Natália de Morais. O papel do amicus curiae no sistema jurídico brasileiro. Revista Consultor Jurídico, São Paulo, 23 jan. 2019. Disponível em:

https://www.conjur.com.br/2019-jan-23/opiniao-papel-amicus-curiae-sistema-juridico-brasileiro. Acesso em: 24 abr. 2020.

CRUZ, Amália Catharina Santos. O embate de projetos na formação de professores de Educação Física: além da dualidade Licenciatura-Bacharelado. 2009. 151f. Dissertação (Mestrado em Educação) - Centro de Ciências da Educação, Universidade Federal de Santa Catarina, Florianópolis, 2009. 
DIAS, Fernanda Braga Magalhães; TEIXEIRA, David Romão. Formação de professores de Educação Física: a atualidade do embate político. Motrivivência, Florianópolis, Ano XXII, n. 35, p. 184-201, dez. 2010.

DIAS JÚNIOR, Elson Moura; LIMA, Thiago Firmino. Aspectos jurídicos da regulamentação da profissão: legalidades e ilegalidades. In: DIAS JÚNIOR, Elson Moura; LIMA, Thiago Firmino (Org.). MNCR: 10 anos na luta pela regulamentação do trabalho. Feira de Santana: UEFS Editora, 2010. p. 65-74.

DIEESE. Nota Técnica $\mathbf{n}^{\mathbf{0}}$ 178: A Reforma Trabalhista e os impactos para as relações de trabalho no Brasil. Mai. 2017. Disponível em: https://www.dieese.org.br/notatecnica/2017/notaTec178reformaTrabalhista.html. Acesso em: 24 abr. 2020.

MASCARO, Alysson Leandro. Estado e Forma Política. São Paulo: Boitempo. 2018.

MBEMBE, Achille. Necropolítica. São Paulo: Editora N-1, 2018.

MÉSZÁROS, István. Para além do capital: rumo a uma teoria da transição. São Paulo: Boitempo Editorial; Editora da Unicamp, 2002.

SILVA, Guilherme Gil et al. Movimento Nacional Contra a Regulamentação do Profissional de Educação Física: resistência contra a ofensiva neoliberal aos trabalhadores. In: ANAIS do III Simpósio de Lutas Sociais da América Latina. UEL: Londrina, 2008.

VALIM, Rafael. Estado de Exceção: a forma jurídica do neoliberalismo. São Paulo: Contracorrente, 2017.

\section{NOTAS DE AUTOR}

AGRADECIMENTOS - Não se aplica.

CONTRIBUIÇÃO DE AUTORIA - Não se aplica

\section{FINANCIAMENTO}

Celi Nelza Zulke Taffarel é Bolsista de produtividade de pesquisa do Conselho Nacional de Desenvolvimento Científico e Tecnológico (CNPq)

Sidnéia Flores Luz é Bolsista da Coordenação de Aperfeiçoamento de Pessoal de Nível Superior (CAPES), processo $\mathrm{n}^{\mathrm{o}} 88887.479742 / 2020-00$

CONSENTIMENTO DE USO DE IMAGEM - Não se aplica

APROVAÇÃO DE COMITÊ DE ÉTICA EM PESQUISA - Não se aplica.

CONFLITO DE INTERESSES - Não se aplica.

\section{LICENÇA DE USO}

Os autores cedem à Motrivivência - ISSN 2175-8042 os direitos exclusivos de primeira publicação, com o trabalho simultaneamente licenciado sob a Licença Creative Commons Attribution Non-Comercial ShareAlike (CC BY-NC SA) 4.0 International. Esta licença permite que terceiros remixem, adaptem e criem a partir do trabalho publicado, desde que para fins não 
comerciais, atribuindo o devido crédito de autoria e publicação inicial neste periódico desde que adotem a mesma licença, compartilhar igual. Os autores têm autorização para assumir contratos adicionais separadamente, para distribuição não exclusiva da versão do trabalho publicada neste periódico (ex.: publicar em repositório institucional, em site pessoal, publicar uma tradução, ou como capítulo de livro), com reconhecimento de autoria e publicação inicial neste periódico, desde que para fins não comerciais e compartilhar com a mesma licença.

\section{PUBLISHER}

Universidade Federal de Santa Catarina. Programa de Pós-Graduação em Educação Física. LaboMídia - Laboratório e Observatório da Mídia Esportiva. Publicado no Portal de Periódicos UFSC. As ideias expressadas neste artigo são de responsabilidade de seus autores, não representando, necessariamente, a opinião dos editores ou da universidade.

\section{EDITORES}

Mauricio Roberto da Silva, Giovani De Lorenzi Pires, Rogério Santos Pereira.

\section{EDITOR DE SEÇÃO}

Giovani de Lorenzi Pires.

\section{REVISÃO DO MANUSCRITO E METADADOS}

João Caetano Prates Rocha; Keli Barreto.

\section{HISTÓRICO}

Recebido em: 13 de março de 2021.

Aprovado em: 03 de maio de 2021. 